\title{
Hardware Simulator Development for a 3-Parallel Grid-Connected PMSG Wind Power System
}

\author{
Kiwoo Park* and Kyo-Beum Lee ${ }^{\dagger}$ \\ ${ }^{\dagger *}$ School of Electrical and Computer Eng., Ajou University, Suwon, Korea
}

\begin{abstract}
This paper presents the development of a hardware simulator for a 3-parallel grid-connected PMSG wind power system. With the development of permanent magnetic materials in recent years, the capacity of a PMSG based wind turbine system, which requires a full-scale power converter, has been raised up to a few MW. Since it is limited by the available semiconductor technology, such large amounts of power cannot be delivered with only one power converter. Hence, a parallel connecting technique for converters is required to reduce the ratings of the converters. In this paper, a hardware simulator with 3-parallel converters is described and its control issues are presented as well. Some experimental results are given to illustrate the performance of the simulator system.
\end{abstract}

Key Words: 3-parallel operation, Hardware simulator, Permanent magnet synchronous generator (PMSG)

\section{INTRODUCTION}

Wind energy is one of the fastest growing renewable energy sources and its corresponding technologies have been studied since the 1970s. As a result of the rapid growth of power electronic technologies, there has been rapid development in wind power technologies since the 1990s and various wind turbine concepts have been developed. With the technological development of wind generator systems, $M W$-level wind generators are being installed nowadays [1].

Wind turbine systems can be classified into three dominant types. One is a constant speed squirrel-cage induction generator (SCIG) based wind turbine system as shown in Fig. 1 (a). The second is a variable speed doubly fed induction generator (DFIG) based wind turbine system and the other is a variable speed permanent magnet synchronous generator (PMSG) based wind turbine system as shown in Fig. 1 (b) and (c), respectively.

Because the SCIG operates only in a narrow range around the synchronous speed, the SCIG based wind turbine system is often called a constant speed wind turbine system. This system is robust, easy to implement and relatively cheap for mass production. However, the speed and reactive power of the system is not controllable and an additional gearbox in the drive train is necessary. As the name of this system implies, it can generate only over a very narrow range of speed around the synchronous speed.

The DFIG based wind turbine system utilizes a wound rotor induction generator (WRIG) and a partial-scale power

\footnotetext{
Manuscript received Mar. 24, 2010; revised Jul. 21, 2010

$\dagger$ Corresponding Author: kyl@ajou.ac.kr

Tel: +82-31-219-2376, Fax: +82-31-212-9531, Ajou University

* School of Electrical and Computer Eng., Ajou University, Korea
}

converter on the rotor side. This system can operate in a speed range of $30 \%$ of the synchronous speed and the rating of the power converter is only $30 \%$ of the generator capacity. This converter can perform reactive power control and has a smooth grid connection. However, the DFIG based wind turbine system still requires a gearbox and a slip ring which requires regular maintenance. Furthermore, since grid fault conditions can easily destroy a power converter, complicated control strategies and protection schemes are required [2]-[5].

With the developments in permanent magnetic materials in recent years, the performance of PMSG based wind turbine systems have been improved and they are widely used. These systems require neither slip rings nor an additional power supply for magnetic field excitation. They can also operate in a relatively wide range of wind speeds. Therefore, their efficiency is known to be higher than that of any of the aforementioned wind turbine systems. However, a PMSG based wind turbine system requires a full-scale power converter which directly connects the generator to the grid. The rating of the power converter is usually limited by available semiconductor technology. One effective way of reducing the power converter's rating requirement is to connect multiple power converters in parallel. If three power converters are connected in parallel, then the capacity of each power converter can be reduced to one third of the total capacity of the wind turbine system [6].

In this paper, the development of a hardware simulator for a $10 \mathrm{~kW}$ 3-parallel grid-connected PMSG based wind turbine system will be described. The wind turbine is modeled with an induction motor which is controlled by a separate vector control motor drive. The reference torque signal under a given wind speed and the measured blade speed is calculated 


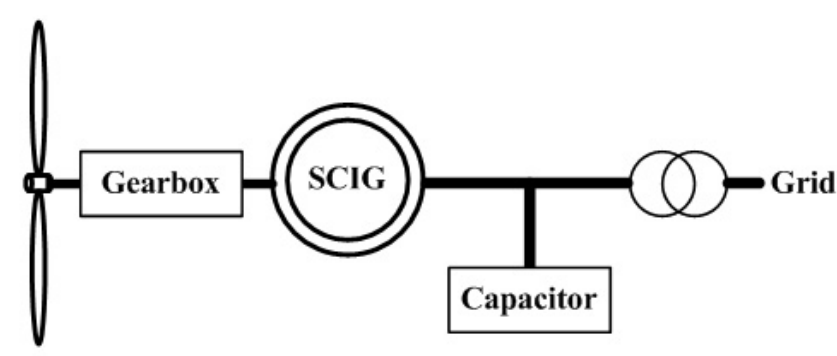

(a)

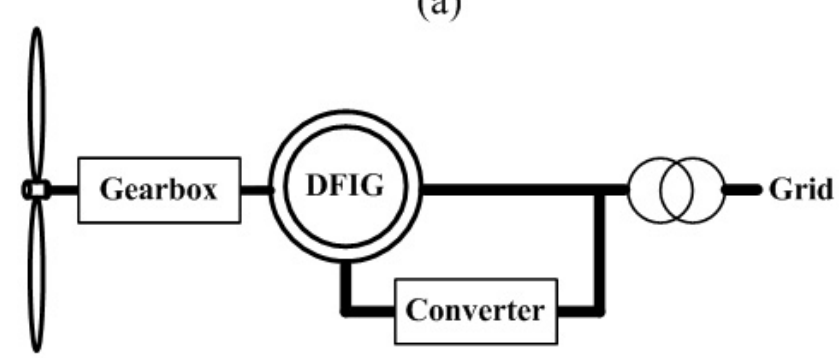

(b)

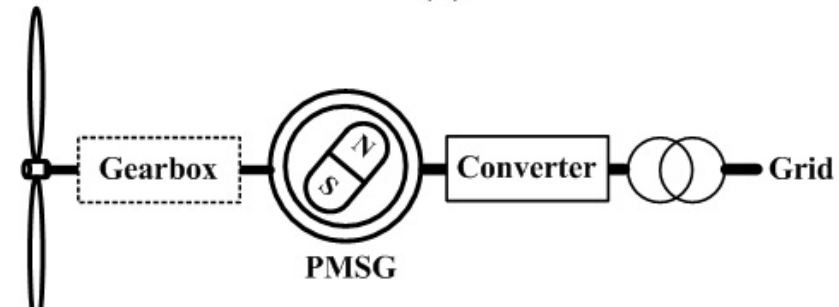

(c)

Fig. 1. (a) Constant speed SCIG based wind turbine system, (b) variable speed DFIG based wind turbine system, and (c) variable speed PMSG based wind turbine system.

and sent from a control board to the motor drive by means of an analog signal. Three parallel back-to-back converters which share a dc-link capacitor are used as a full-scale power converter and an LCL-filter is employed as an output filter.

\section{PROPOSED HARDWARE SIMULATOR}

The proposed hardware configuration of the simulator for a 3-parallel grid-connected PMSG wind power system is shown in Fig. 2. The simulator models a blade and a PMSG with a motor-generator set (MG-set). A power conversion module of the simulator includes a 3-parallel generator-side converter which controls the generator and a 3-parallel gridside converter which controls the dc-link voltage and performs as a grid-connection. An LCL-filter is employed to suppress the output current ripples effectively. The overall power system is controlled by a controller unit which is implemented with a DSP, a FPGA and other peripheral circuits. The ratings of the simulator are summarized in Table I.

\section{A. Motor-Generator Set}

A $15 \mathrm{~kW}$ induction motor with a separate induction motor drive (Yaskawa Varispeed G7) is used to model the mechanical characteristics of a wind turbine. The supplied torque from the blade to the PMSG can be calculated with (1) [7].
TABLE I

RATINGS OF THE SIMULATOR SYSTEM

\begin{tabular}{|l|c|}
\hline rated generator speed & $1500 \mathrm{rpm}$ \\
rated generator torque & $63.66 \mathrm{~N} \cdot \mathrm{m}$ \\
rated generator power & $10 \mathrm{~kW}$ \\
rated generator voltage & $220 \mathrm{~V}_{r m s}$ \\
rated generator current & $26.24 \mathrm{~A}_{r m s}$ \\
rated current of each leg on generator-side & $8.74 \mathrm{~A}_{r m s}$ \\
dc-link voltage & $600 \mathrm{~V}$ \\
grid voltage & $380 \mathrm{~V}_{r m s}$ \\
rated grid current & $15.19 \mathrm{~A}_{r m s}$ \\
rated current of each leg on grid-side & $5.06 \mathrm{~A}_{r m s}$ \\
switching frequency & $2 \mathrm{kHz}$ \\
& \\
\hline
\end{tabular}

$$
T_{\text {blade }}=\frac{P_{\text {blade }}}{\omega_{\text {blade }}}=\frac{1}{2} A \rho V_{\text {wind }}{ }^{3} \frac{C_{p}}{\omega_{\text {blade }}}
$$

where, $A$ is the circular area of the blade, $\rho$ is the air density, $V_{\text {wind }}$ is the velocity of the wind, $C_{p}$ is the power coefficient, and $\omega_{\text {blade }}$ is the rotational speed of the blade. The power coefficient, $C_{p}$, is the value which tells how efficiently a turbine converts the energy in wind to mechanical energy and is dependent upon the physical design and the pitch control of the blade. Therefore, $C_{p}$ curves vary with the type of the blade. The $C_{p}$ curve is a function of the tip speed ratio, $\lambda$, and Fig. 3 shows the $C_{p}$ curve used in this paper.

$$
\lambda=\frac{\omega_{\text {blade }} R_{\text {blade }}}{V_{\text {wind }}}
$$

where $R_{\text {blade }}$ is the radius of the blade.

The calculated torque for the turbine is converted into the corresponding analog signal through the D/A converter in the control board and sent to the induction motor drive which will control the torque of the induction motor.

\section{B. Power Converter Modules}

The power converter modules are comprised of a 3-parallel generator-side converter and a 3-parallel grid-side converter. These converters are connected to a common dc-link capacitor. As mentioned above, the individual low power converters are connected in parallel to make up a high power converter. An intelligent power module (IPM, Mitsubishi PM150RL1A120), which consists of 7 IGBT switches (6 for converter bridges and 1 for the braking operation), gate drivers, and protection circuits, is used as an individual low power converter. The PWM switching signals from the control board drive each of the IPMs through the IPM interface board and a fault signal from the IPMs is sent back to the control board to protect the system.

Due to the small differences in the characteristic of the switches and the pulse signal, a small inductor $L_{\text {inner }}$ at each ac side leg is required to prevent a shoot-through as shown in Fig. 2 [3].

To control the currents of the generator and the grid, 3 current sensors for each side $\left(I_{a s}, I_{b s}, I_{c s}\right.$ and $\left.I_{a}, I_{b}, I_{c}\right)$ are installed. In addition, to control the zero-sequence circulating current caused by the slight difference between the inner inductors, 18 current sensors $\left(I_{a b c s_{-} 1}, I_{a b c s_{-} 2}, I_{a b c s_{-} 3}\right.$ and $\left.I_{a b c_{-} 1}, I_{a b c_{-} 2}, I_{a b c_{-} 3}\right)$ for each parallel branch of both sides are 


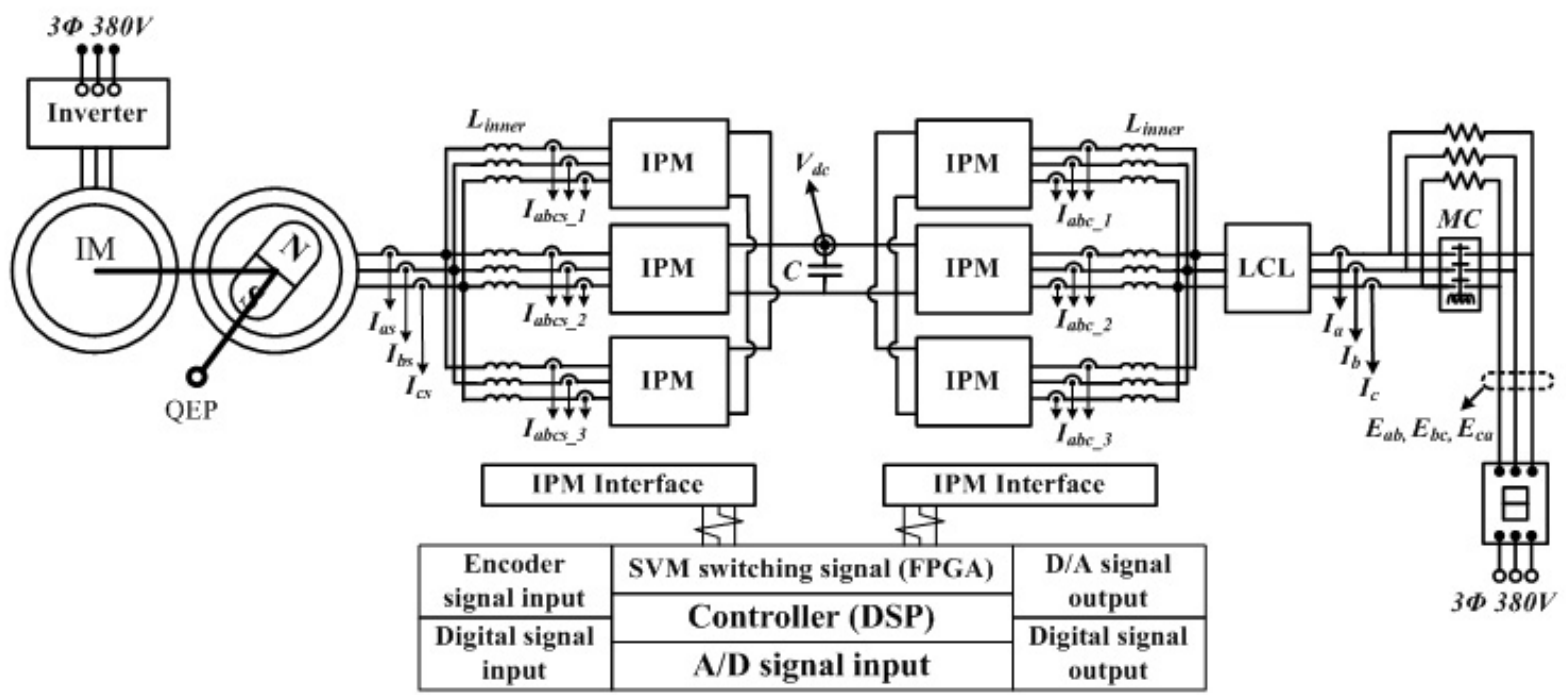

Fig. 2. Proposed hardware configuration of the simulator for the 3-parallel grid connected PMSG wind power system.

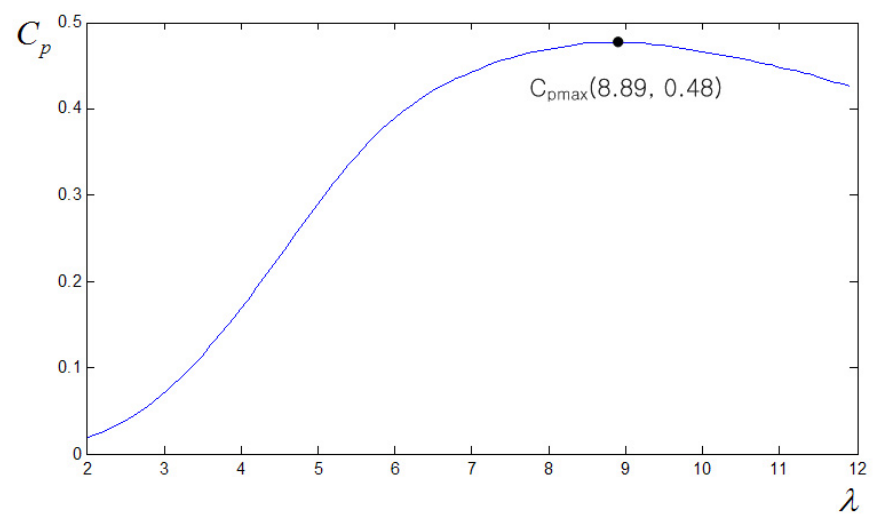

Fig. 3. Power coefficient curve with respect to the tip speed ratio.

installed. Furthermore, 4 voltage sensors $\left(V_{d c}, E_{a b}, E_{b c}\right.$, and $E_{c a}$ ) are installed to measure the dc-link voltage and the lineto-line voltages of the grid. These measured values are used to control the dc-link voltage and to perform a grid connection.

\section{LCL-Filter}

In a high power system, the switching frequency of the converter is usually restricted to between 1 to $3 \mathrm{kHz}$. This relatively low switching frequency may cause an increase in the output current harmonics which can disturb the other sensitive loads on the same grid. Therefore, the harmonics generated from the grid-connected converter are restricted by the standard (IEEE 519-1002) [8].

A proper filter has to be designed to reduce the output current harmonics to a level which satisfies this standard. An LCL-filter is one of the best candidates for a high power system because the inductance required is smaller than that of L- or LC-filters to achieve the same performance [9]. An LCL-filter can be constructed in two different configurations, namely $\Delta$-connected and $Y$-connected LCL-filters as shown in Fig. 4.

As can be seen from the single-phase equivalent circuits, the $\Delta$-connected LCL-filters require one-third of the capacitance when compared to the $Y$-connected LCL-filters. In other words, with the same capacitance, the resonance frequency of the $\Delta$-connected LCL-filters is $1 / \sqrt{3}$ times lower than that of the $Y$-connected LCL-filters, which means that a reduction in the output current harmonics near the switching frequency is more effective with the $\Delta$-connected LCL-filter.

$$
\begin{gathered}
f_{\text {res.Y }} \cong \frac{1}{2 \pi} \sqrt{\frac{L_{1}+L_{2}}{L_{1} L_{2} C_{f}}} \\
f_{\text {res. } .} \cong \frac{1}{2 \pi} \sqrt{\frac{L_{1}+L_{2}}{3 L_{1} L_{2} C_{f}}} .
\end{gathered}
$$

However, the $\Delta$-connected LCL-filters require $\sqrt{3}$ times more rated voltage.

\section{Control Board}

The simulator is controlled by a controller unit which is implemented with a DSP (TMS320F28335), a FPGA (Cyclone III EP3C25Q240C8N) and other peripheral circuits as shown in Fig 5.

The DSP communicates with a computer through a JTAG and/or RS232 serial communication. The reference torque for the induction motor drive is calculated by the DSP with a mathematical model considering the tip speed ratio and then it is transferred to the drive by means of an analog signal. The quadrature encoder pulse (QEP) signal, which represents the rotational angle of the blade, is fed to the DSP after passing through a low pass filter to eliminate the noises and then the speed of the blade is calculated.

To control the power module of the system, the controller has to be able to drive the 6 IPMs independently, which means that 36 separate PWM channels are required. Unfortunately, 

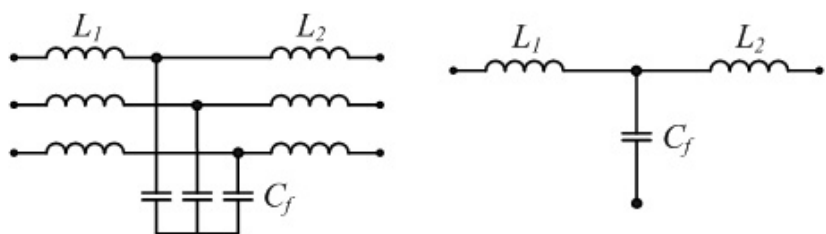

(a)
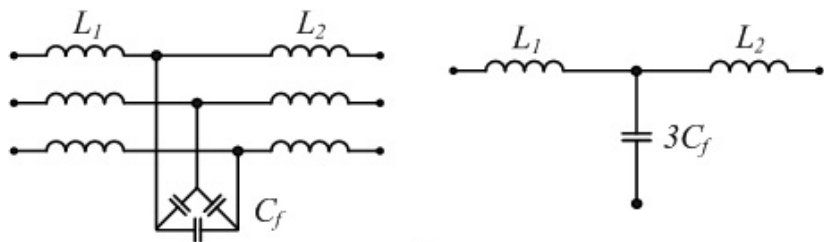

(b)

Fig. 4. LCL-filters with their single-phase equivalent circuits: (a) $Y$-connected and (b) $\Delta$-connected.

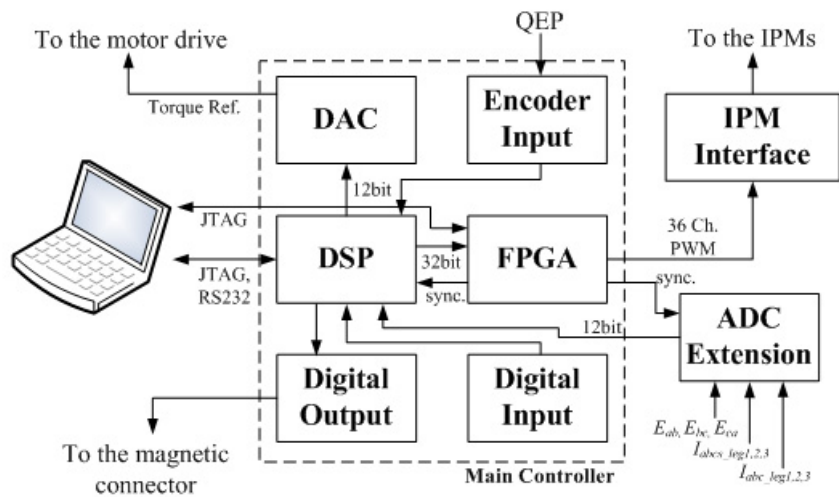

Fig. 5. Functional block diagram of the controller unit.

the TMS320F28335 only offers 18 PWM outputs. Hence, an additional FPGA which communicates with the DSP through a 32-bit data bus is employed. The FPGA receives 36 calculated switching on-off times from the DSP and produces corresponding PWM signals. The FPGA also provides a synchronizing signal to the DSP. With this synchronizing signal, the ADC gets new measured values and the DSP starts a new control period. Therefore, the control frequency is twice as high as the switching frequency. Fig. 6 shows an example waveform of the PWM signal generated by the FPGA. The IPM interface board is also implemented to provide isolation and to match the voltage level of the PWM signals since the FPGA produces positive logic $3.3 \mathrm{~V}$ PWM signals but the IPM requires negative logic $15 V$ PWM signals.

As mentioned above, to control the zero-sequence circulating current caused by the slight differences in the sharing inductors, additional current sensors are required at every inner leg of the power converters as shown in Fig 2. Therefore, the total number of ADC channels required is 28 (18 for the inner currents, 6 for the outer currents, 3 for the grid voltage, and 1 for the dc-link voltage). Unfortunately, the TMS320F28335 offers only 16 ADC channels. Therefore, a separate ADC extension board is implemented. This extension board provides 40 channels of ADC inputs and performs sample-and-hold at

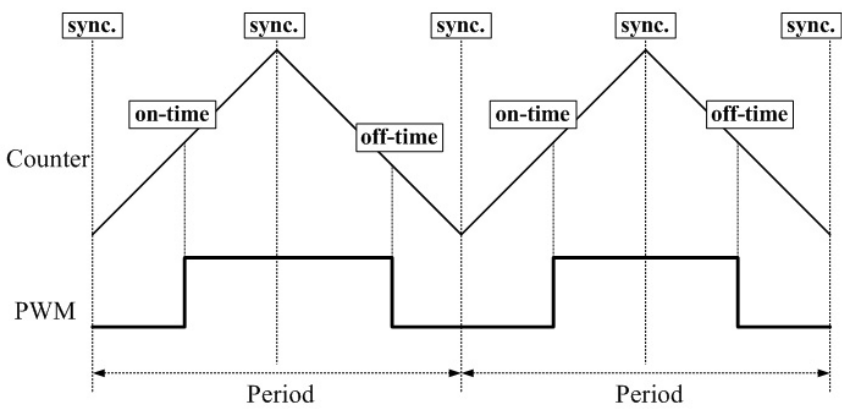

Fig. 6. Example waveform of the PWM signal generated in the FPGA.

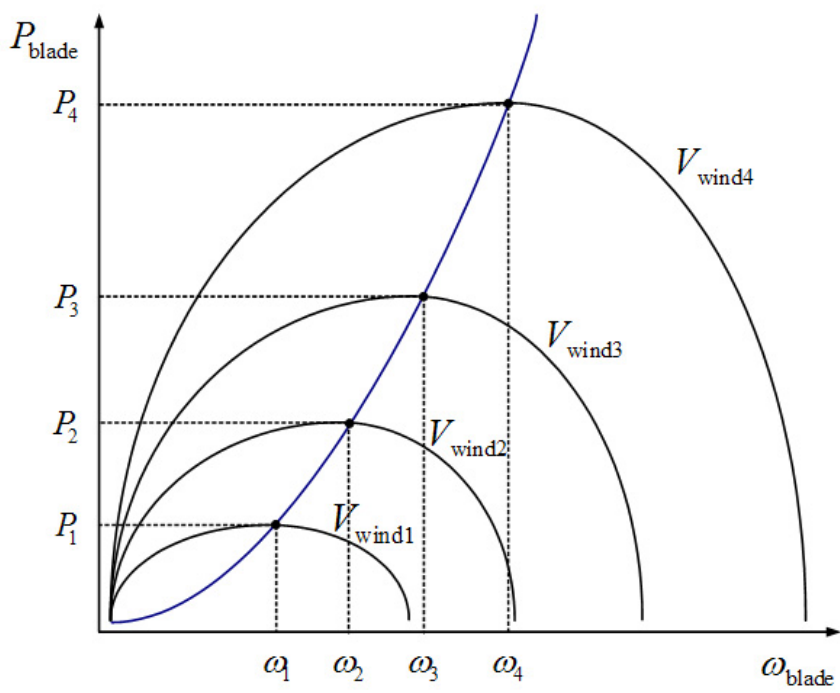

Fig. 7. MPPT operational curves.

the same time that it receives a synchronizing signal from the FPGA. The analog signals are, then, converted into 12-bit digital signals and transferred to the DSP.

Other peripheral circuits such as a digital signal output which controls the magnetic connector on the grid side, a digital signal input, isolation circuits and protection circuits are implemented in the control board as well.

\section{CONTROL STRATEGIES}

For 3-parallel operation of a PMSG system, there are mainly two different control strategies; One is an inner control strategy and the other is an outer control strategy. Both of the control strategies for generator-side converters and gridside converters are explained respectively. Furthermore, other control topics which are indispensable for a PMSG wind power system will be briefly explained.

\section{A. Generator-side Control}

As mentioned in section II.A, the generated power from the blade is a function of the wind speed and the power coefficient which is, in turn, a function of the tip speed. A graph of the generated power according to the wind speed and the rotational speed of the generator can be seen in Fig. 7 . 


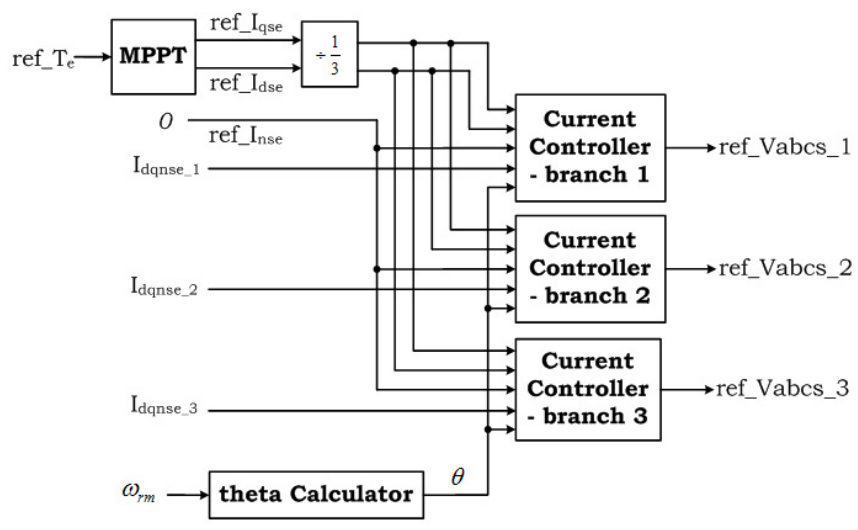

Fig. 8. Block diagram of the inner control scheme for the generator-side.

To obtain as much power from the generator as possible, a generator-side converter has to perform a control which is called maximum power point tracking (MPPT). MPPT is a process where, under a certain wind speed, the rotational speed of a generator is adjusted to a certain value so that the power from the blade can be at its maximum. For example, assume that the wind speed is $V_{\text {wind } 1}$ and that the rotational speed is $\omega 1$, so that the power from the blade is $P_{1}$ at a certain instance. Now, if the wind speed changes from $V_{\text {wind } 1}$ to $V_{\text {wind } 2}$, then the rotational speed of blade should be adjusted to $\omega_{2}$ by controlling the torque of the generator. Many useful MPPT methods are already available in the literatures [10].

According to the positions of the current sensors and the number of current controllers, the current control methods for 3-parallel operation in the generator-side can be divided into two types. One is an inner control and the other is an outer control. Fig. 8 shows a block diagram of the inner control scheme for the generator-side.

The inner control scheme requires the measurement of all the phase currents of each parallel branch. In addition, separate current controllers are dedicated to each of the branches. The current controller is realized with a general PI (Proportionalintegral) controller. The main purpose of this control scheme is to control the current of each branch separately so that the same amount of current can flow in each of the branches suppressing the zero-sequence circulating current. The zerosequence circulating current which will be modeled mathematically in a later section can be easily controlled by modeling it as an $\mathrm{N}$-axis (neutral-axis) component in each of the current controllers [11]. However, this method has two obvious disadvantages since many current sensors are required and three separate current controllers will raise the burden of the DSP.

The other control scheme is the outer control scheme whose block diagram is shown in Fig. 9. This control scheme only requires measuring the outer currents $\left(I_{a s}, I_{b s}\right.$ and $\left.I_{c s}\right)$ which actually flow from the generator. Hence, it utilizes only one current controller. As a result, all the parallel branches share the same PWM signal, which means that the circulating current caused by the differences in the switching times among the parallel branches will not occur. Although this control scheme is much simpler and alleviates the burden of the DSP,

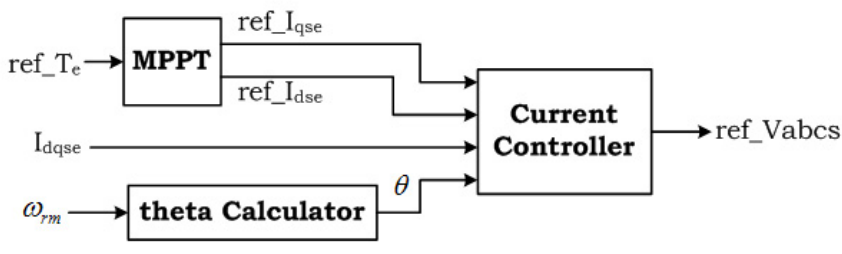

Fig. 9. Block diagram of the outer control scheme for the generator-side.

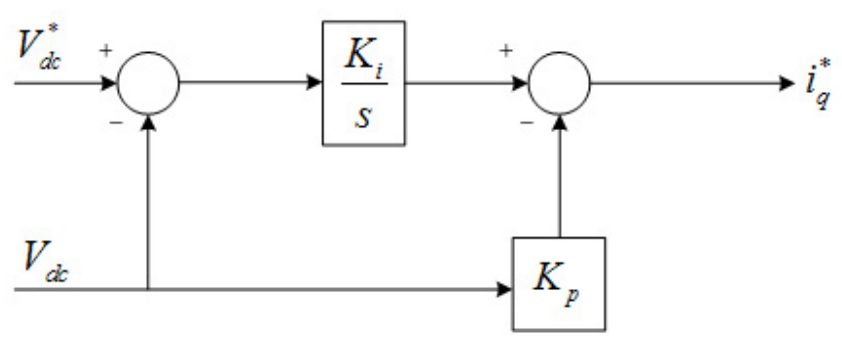

Fig. 10. Block diagram of the IP controller.

it still cannot control the circulating current caused by slight differences in the inner inductors and the characteristic of the switches. Therefore, an optimal control scheme for 3-parallel operation should be studied using the proposed simulator in the future.

\section{B. Grid-side Control}

The grid-side converter controls not only the dc-link voltage but also the power factor to transmit the generated power to the grid efficiently. A fault ride-through capability is also required to avoid a significant loss of wind power production in the event of grid faults.

Before performing a grid connection, the synchronizing phase angle of the grid should be known. This can be easily detected by using a phase locked loop (PLL) algorithm. Many PLL algorithms are already available in the literatures [12].

Unlike the current controller, an IP (Integral-proportional) controller is utilized to control the dc-link voltage as shown in Fig. 10. The IP controller does not include zeros in its transfer function, which means that any overshoot under the influence of zeros does not appear in an IP controller. Therefore, under the same overshoot restriction, the IP controller can have much bigger gains than the PI controller.

The dc-link voltage can be controlled by controlling the active power entering and exiting the dc-link capacitor. In other words, if the entering active power is bigger than the exiting active power, then the dc-link voltage will rise, and vice versa. Since the q-axis current of the grid-side converter is directly proportional to the active power, the dc-link voltage can be controlled by controlling this q-axis current.

The grid-side converter is also made in the form of 3parallel to reduce the power ratings of the converter to one third. Hence, two different control schemes (the inner control and the outer control) can be applied in a similar way to the generator-side. Fig. 11 shows a block diagram of the inner control scheme for the grid-side.

This control scheme requires measuring all of the leg currents of each parallel branch and separate dedicated current 


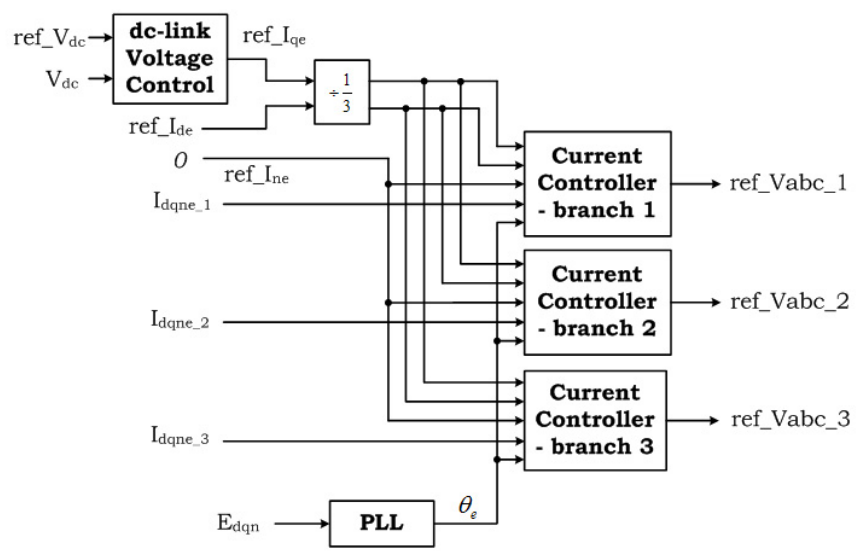

Fig. 11. Block diagram of the inner control scheme for the grid-side.

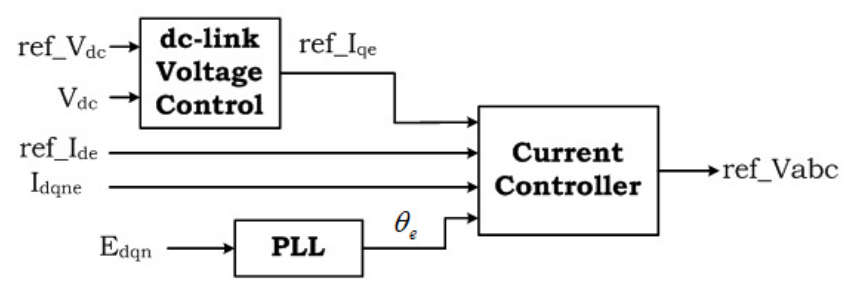

Fig. 12. Block diagram of the outer control scheme for the grid-side.

controllers for each of the branches. Although this control scheme requires many current sensors and raises the burden of the DSP calculation, the zero-sequence circulating current, which can destroy the converter unless it is properly controlled, can be controlled by modeling it as an $\mathrm{N}$-axis component in each of the current controllers.

Fig. 12 shows a block diagram of the outer control scheme for the grid-side. Again, this control scheme is much simpler and alleviates the burden of the DSP, but it still cannot control the circulating current.

\section{Zero-Sequence Circulating Current in a 3-Parallel System}

In this section, the zero-sequence circulating current caused by different switching among the parallel branches in the inner control scheme will be modeled mathematically. Let $s_{1 x}, s_{2 x}$, and $s_{3 x}$ be the switching functions of converter branch 1 , branch 2 and branch 3 , respectively. Also let $x=a, b, c$ represent each leg of a branch. For example, if $s_{1 x}=1$, the upper switch of phase $x$ in branch 1 is on and if $s_{2 x}=-1$, the lower switch of phase $x$ in branch 2 is on. Assuming that the inner inductors have the same inductance, $L$, the following differential equations can be obtained according to Kirchhoff's voltage law.

$$
\left\{\begin{array}{l}
L \frac{d i_{1 a}}{d t}+s_{1 a} \frac{V_{d c}}{2}=L \frac{d i_{2 a}}{d t}+s_{2 a} \frac{V_{d c}}{2}=L \frac{d i_{3 a}}{d t}+s_{3 a} \frac{V_{d c}}{2} \\
L \frac{d i_{1 b}}{d t}+s_{1 b} \frac{V_{d c}}{2}=L \frac{d i_{2 b}}{d t}+s_{2 b} \frac{V_{d c}}{2}=L \frac{d i_{3 b}}{d t}+s_{3 b} \frac{V_{d c}}{2} \\
L \frac{d i_{1 c}}{d t}+s_{1 c} \frac{V_{d c}}{2}=L \frac{d i_{2 c}}{d t}+s_{2 c} \frac{V_{d c}}{2}=L \frac{d i_{3 c}}{d t}+s_{3 c} \frac{V_{d c}}{2}
\end{array} .\right.
$$

Now, define the zero-sequence circulating currents, $i_{10}$ and $i_{20}$, and the zero-sequence switching functions, $s_{10}, s_{20}$, and $s_{30}$ as:

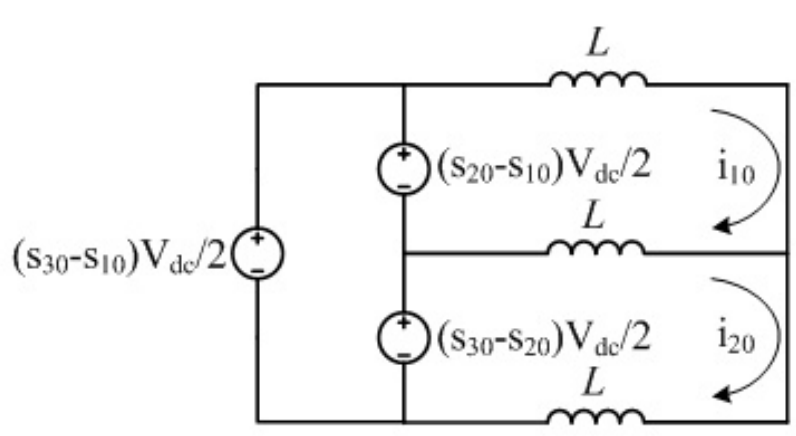

Fig. 13. Circulating current equivalent circuit of the 3-parallel converters.

$$
\left\{\begin{array}{c}
i_{10}=\left(i_{1 a}+i_{1 b}+i_{1 c}\right) / 3 \\
i_{20}=-\left(i_{3 a}+i_{3 b}+i_{3 c}\right) / 3 \\
i_{20}-i_{10}=\left(i_{2 a}+i_{2 b}+i_{2 c}\right) / 3 \\
s_{10}=\left(s_{1 a}+s_{1 b}+s_{1 c}\right) / 3 \\
s_{20}=\left(s_{2 a}+s_{2 b}+s_{2 c}\right) / 3 \\
s_{30}=\left(s_{3 a}+s_{3 b}+s_{3 c}\right) / 3
\end{array} .\right.
$$

From (4) and (5), the following equation can be obtained and its equivalent circuit is shown in Fig. 13.

$$
\left\{\begin{array}{l}
L \frac{d}{d t}\left(2 i_{10}-i_{20}\right)=\left(s_{20}-s_{10}\right) \frac{V_{d c}}{2} \\
L \frac{d}{d t}\left(2 i_{20}-i_{20}\right)=\left(s_{30}-s_{20}\right) \frac{V_{d c}}{2} \\
L \frac{d}{d t}\left(i_{10}+i_{20}\right)=\left(s_{30}-s_{10}\right) \frac{V_{d c}}{2}
\end{array} .\right.
$$

Therefore, the zero-sequence circulating current during one switching period is

$$
\left\{\begin{array}{l}
i_{10}=\int_{0}^{T} \frac{V_{d c}}{6 L}\left(s_{20}+s_{30}-2 s_{10}\right) d t \\
i_{20}=\int_{0}^{T} \frac{V_{d c}}{6 L}\left(2 s_{30}-s_{10}-s_{20}\right) d t
\end{array} .\right.
$$

\section{EXPERIMENTS}

The hardware simulator which is introduced in chapter II has been built and Fig. 14 shows actual pictures of the system. The simulator consists of a MG-set, a power converter module, an LCL-filter, and a control board. Table 2 shows the circuit parameters used for this simulator. Additional damping resistors are used in the LCL-filter to avoid resonance.

Fig. 15 shows the experimental steady-state waveforms of the angular speed of the generator, the reference torque, and the generated power when a $9 \mathrm{~m} / \mathrm{s}$ wind is applied to the simulator. The angular speed is about $1150 \mathrm{rpm}$ and the calculated reference torque is about $-45 \mathrm{~N} \cdot \mathrm{m}$ considering the MPPT. With this torque applied to the generator, about 5880 $W$ is generated. The negative values of the torque and the power mean the generator is operating in a generating-mode. The outer control schemes are used for both the generator-side and the grid-side converters in this experiment.

Fig. 16 and Fig. 17 show the waveforms of the phase current and the line-to-line voltage on the generator-side and the gridside, respectively, under the same conditions. Both of the lineto-line voltages are synthesized with the same dc-link voltage, $600 \mathrm{~V}$, which is controlled by the grid-side converter. The 


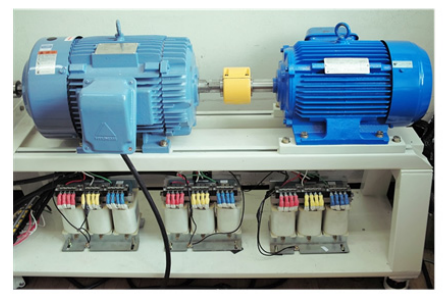

(a)

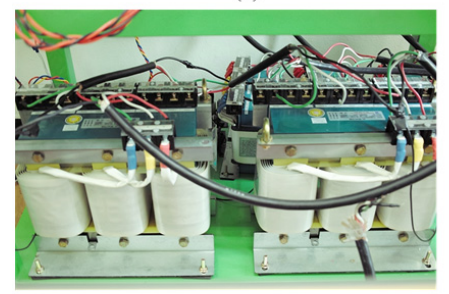

(c)

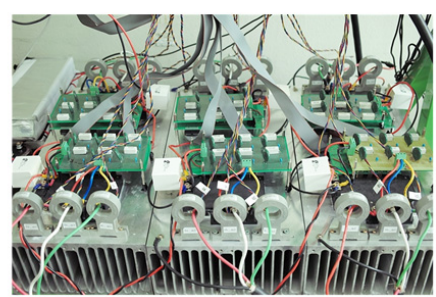

(b)

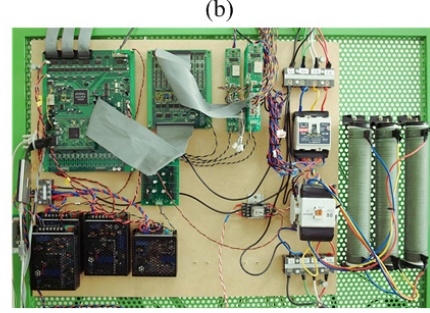

(d)
Fig. 14. Actual hardware simulator: (a) M-G set, (b) Power converter modules, (c) LCL-filter, (d) Control unit.

TABLE II

RATINGS OF THE SIMULATOR SYSTEM

\begin{tabular}{|l|l|c|}
\hline Power Converter & $L_{\text {inner }}$ & $2 \mathrm{mH}$ \\
Module & dc-link capacitance & $3300 \mu \mathrm{F}$ \\
\hline \multirow{3}{*}{ LCL-filter } & $L_{1}$ & $4 \mathrm{mH}$ \\
& $L_{2}$ & $4 \mathrm{mH}$ \\
& $C_{f_{-} \Delta}$ & $7.5 \mu \mathrm{F}$ \\
& $R_{f_{-} \Delta}$ & $9 \Omega$ \\
\hline
\end{tabular}
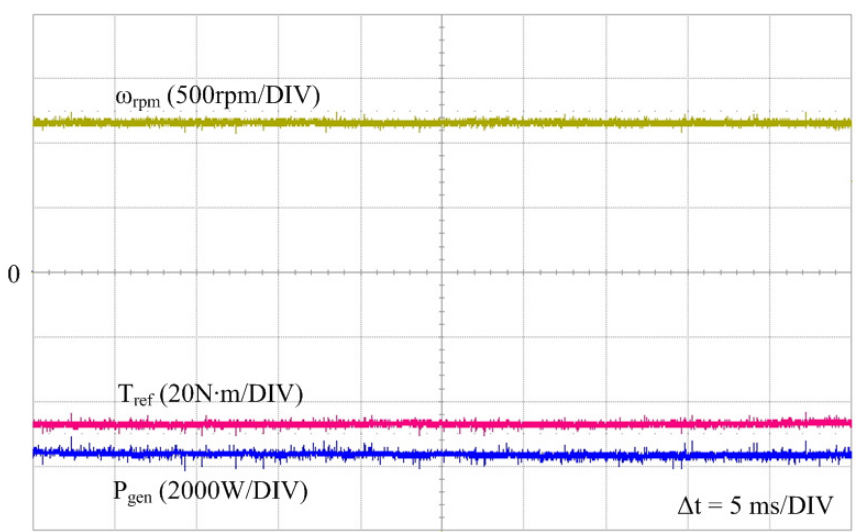

Fig. 15. Experimental waveforms of the angular speed of generator, the reference torque, and the generated power when the speed of the wind is $9 \mathrm{~m} / \mathrm{s}$.

sinusoidal currents are flowing on both sides of the converter at the corresponding frequencies. Fig. 18 shows the waveform of the phase current filtered by an LCL-filter. It can be seen that the current harmonics are well suppressed by the LCLfilter.

Fig. 19 shows the transient-state waveforms of the speed of the wind, the generated power, the phase current of the grid, and the dc-link voltage when the speed of the wind is varied from 4 to $9 \mathrm{~m} / \mathrm{s}$ with the MPPT control. As the speed of the wind rises, the amount of torque that is transferred from the blade to the generator rises. With the MPPT control mentioned in the previous chapter, the speed of the blade is controlled to maintain a power coefficient that is as high as possible. As a result, the generated power is increased from

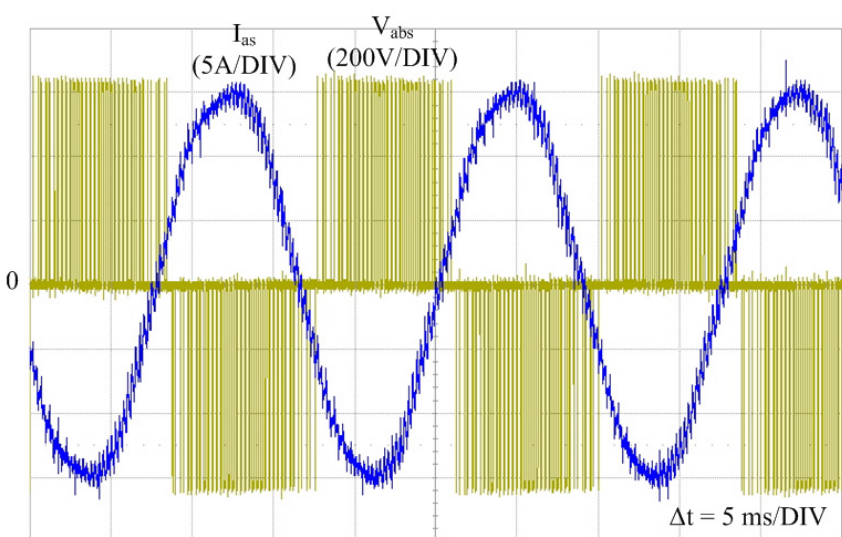

Fig. 16. Experimental waveforms of the phase current and the line-to-line voltage in the generator-side.

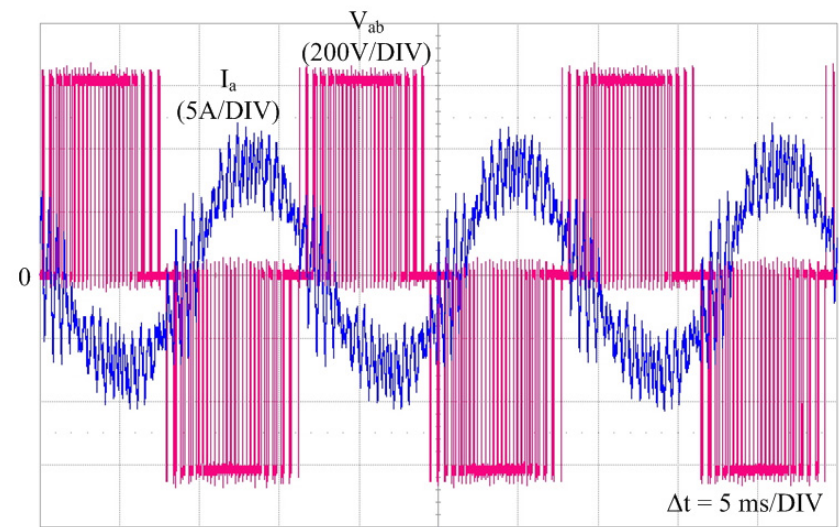

Fig. 17. Experimental waveforms of the phase current and the line-to-line voltage in the grid-side.

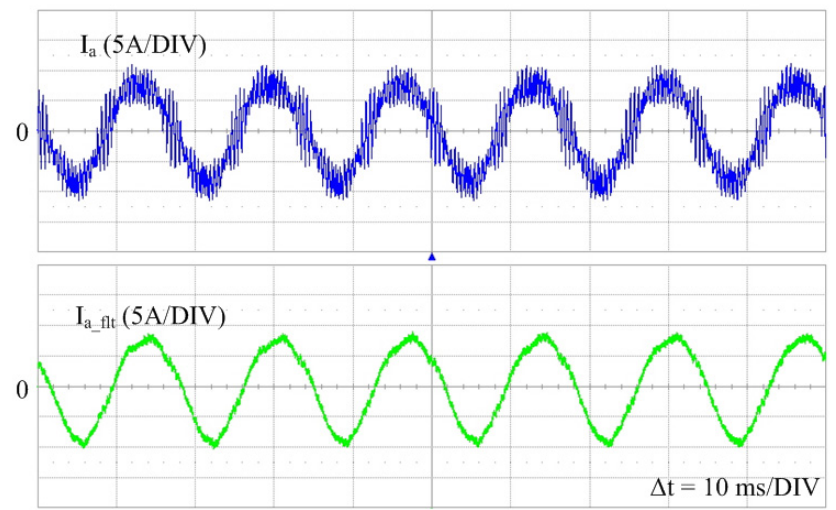

Fig. 18. Experimental waveforms of the phase current filtered by the LCL-filter: (top) unfiltered and (bottom) filtered.

$3.1 \mathrm{~kW}$ to $5.9 \mathrm{~kW}$. The third waveform shows that the grid current increases as the generated power increases and the fourth waveform shows that the dc-link voltage is controlled at $600 \mathrm{~V}$ regardless of the amount of power produced.

\section{CONCLUSIONS}

In this paper, the development of a hardware simulator for a 3-parallel grid-connected PMSG wind power system was 


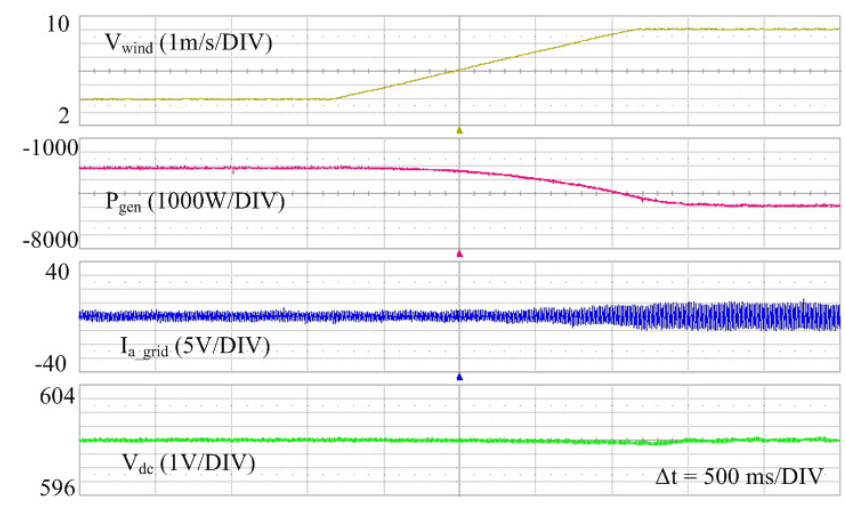

Fig. 19. Experimental waveforms of the wind speed, the generated power, the phase current in the grid-side, and the dc-link voltage when the wind speed is changed from 4 to $9 \mathrm{~m} / \mathrm{s}$.

described. The hardware components of the simulator were described and its control schemes regarding 3-parallel operation were explained. An actual $10 \mathrm{~kW}$ hardware simulator was built in the laboratory and several experiments were carried out to verify the operational feasibility of the simulator. The developed simulator can be utilized to analyze the various mechanical and electrical characteristics of a 3-parallel gridconnected PMSG wind power system and to verify optimal control schemes in future research.

\section{ACKNOWLEDGMENT}

This work was supported by a National Research Foundation of Korea (NRF) grant funded by the Korea government (MEST) (No.20100011933).

\section{REFERENCES}

[1] H. Li and Z. Chen, "Overview of different wind generator systems and their comparisons," IET Renewable Power Generation, Vol. 2, Issue 2, pp. 123-138, Jun. 2008.

[2] S. Muller, M. Deicke, and R.W. De Doncker, "Doubly fed induction generator systems for wind turbines," IEEE Trans. on Industry Applications Magazine, Vol. 8, Issue 3, pp. 26-33, May/Jun. 2002.

[3] G.G. Park, S.H. Hwang, J.M. Kim, K.B. Lee, and D.C. Lee, "Reduction of current ripples due to current measurement errors in a doubly fed induction generator," Journal of Power Electronics, Vol. 10, No. 3, pp. 313-319, May 2010.
[4] S.T. Jou, S.B. Lee, Y.B. Park, and K.B. Lee, "Direct power control of a DFIG in wind turbines to improve dynamic responses," Journal of Power Electronics, Vol. 9, No. 5, pp.781-790, Sep. 2009.

[5] Y.S. Kim, A. Marathe, and D.J. Won, "Comparison of various methods to mitigate the flicker level of DFIG in considering the effect of grid conditions," Journal of Power Electronics, Vol. 9, No. 4, pp.612-622, Jul. 2009.

[6] F. Tang, X. Jin, Y. Tong, J. Liu, F. Zhou, and L. Ma, "Parallel interleaved grid-connected converters in MW-level wind power generation," Proc. of IEMDC, pp 789-796, May 2009.

[7] B. Han, H. Lee, and D. Yoon, "Hardware simulator development for PMSG wind power system," Proc. of PES, pp. 1-6, Jul. 2009.

[8] I.J. Gabe, V.F. Montagner, and H. Pinheiro, "Design and implementation of a robust current controller for VSI connected to the grid through an LCL filter," IEEE Trans. on Power Electronics, Vol. 24, No. 6, pp. 14441452, Jun. 2009.

[9] H.G. Jeong, K.B. Lee, S. Choi, and W. Choi, "Performance improvement of LCL-filter based grid connected-inverters using PQR power transformations," IEEE Transactions on Power Electronics, Vol. 25, No. 5, pp. 1320-1330, May 2010.

[10] E. Koutroulis and K. Kalaitzakis, "Design of a maximum power tracking system for wind-energy-conversion applications," IEEE Trans. on Industrial Electronics, Vol. 53, Issue 2, pp. 486-494, Apr. 2006

[11] W. Hu, Y. Wang, W. Yao, H. Zhang, J. Wu, and Z. Wang, "Modeling and control of zero-sequence current in multiple grid connected converter," Proc. of PESC, pp. 2062-2069, Jun. 2008.

[12] F.D. Freijedo, J. Doval-Gandoy, O. Lopez, and J. Cabaleiro, "Robust phase locked loops optimized for DSP implementation in power quality applications," Proc. of IECON, pp. 3052-3057, Nov. 2008.

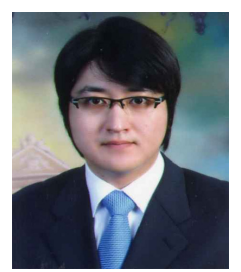

Kiwoo Park was born in Inchon, Korea, in 1981. He received his B.S. in Electrical and Computer Engineering from Ajou University, Suwon, Korea, in 2009. He is currently working toward his M.S. at Ajou University. His research interests include power conversion and electric machine drives.

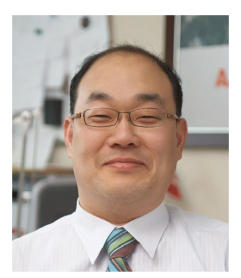

Kyo-Beum Lee was born in Seoul, Korea, in 1972. He received his B.S. and M.S. in Electrical and Electronic Engineering from Ajou University, Korea, in 1997 and 1999, respectively. He received his Ph.D. in Electrical Engineering from Korea University, Korea in 2003. From 2003 to 2006, he was with the Institute of Energy Technology, Aalborg University, Aalborg, Denmark. From 2006 to 2007, he was with the Division of Electronics and Information Engineering, Chonbuk National University, Jeonju, Korea. In 2007 he joined the School of Electrical and Computer Engineering, Ajou University, Suwon, Korea. He is an Associated Editor of the IEEE Transactions on Power Electronics and the Journal of Power Electronics. His research interests include electric machine drives and wind power generation. 